\title{
MODELING INTERGROUP CONFLICT AS STRATEGIC INTERACTIONS
}

\author{
Károly TAKÁCS ${ }^{1}$ \\ Budapest University of Economic Sciences and Public Administration \\ Budapest, Fővám tér 8. H-1093; e-mail: karoly.takacs@bkae.hu
}

\begin{abstract}
Conflicts between groups are among the central research problems in the social sciences. Several theoretical models have been proposed previously to understand and explain their causes, emergence, and dynamics. None of these models, however, captured the unintended nature of these conflicts as a result of individual actions and the structural embeddedness of actions at the same time. This study proposes such a framework as it integrates two-level models of intergroup relations known as team games and models of dyadic social control mechanisms. The proposed model demonstrates why and under what structural conditions can intergroup conflicts be considered as social dilemmas. Model predictions can be derived about the relation between certain properties of the social network and likelihood of intergroup conflict. In particular, the model provides an explanation why intergroup conflicts are often promoted by segregation and also describes some conditions under which the segregation effect becomes weaker.
\end{abstract}

Keywords: intergroup conflict, team games, structural embeddedness, social networks, social control, segregation

\section{INTRODUCTION}

Individuals, despite the likelihood of being harmed, often join intergroup fights voluntarily. They could free ride easily on the effort of others and enjoy the benefits from intergroup rivalry; still many of them play an active role in competitive actions of their group. Therefore, in a pursuit for the conditions under which intergroup conflict emerges, social science research has to ascertain why group members are willing to participate in harmful intergroup competitions. The underlying mechanisms have to be explored that drive individuals towards sacrifices against another group.

In general, little has been said previously about the social mechanisms that lead to participation in intergroup conflict. As a major contribution, this study aims to

* This paper is largely based on a research that has been conducted while the author was a Ph.D. student at the Interuniversity Center for Social Science Theory and Methodology (ICS) in Groningen.

1 I would like to thank Frans Stokman, Roel Popping, Wim Liebrand, and Andreas Flache for their valuable and thorough advises, comments, and criticisms. I also thank Carlijne Philips, Justine Horgan, Thomas Gautschi, Henk Flap, Harry Ganzeboom, , and an anonymous referee of the Review of Sociology for their comments. 
highlight causal chains that stem from the embeddedness of human action (Granovetter 1985). Individual decisions in the intergroup context are interdependent, embedded in the social structure, and embedded in a historical context. They are interdependent, because contribution to harmful intergroup competition has an effect on intergroup relations and consequently on the well being of others. Moreover, it has also a direct effect on actions that others undertake. Such influences are especially strong among friends, neighbors, colleagues, and family members, which means that the network of individual relationships constrains individual actions. This explains why structural embeddedness has an impact on intergroup relations. On the other hand, lethal clashes in the past and prospects of future relations have firm effects on present attitudes and actions in the intergroup context. This is the reason why temporal embeddedness plays a crucial role in intergroup competitions.

The question of how interdependence and embeddedness influence decisions in the intergroup context and consequently the outcome of intergroup relations is central in this study. This question frames the theoretical model building in this research. Among effects of structural embeddedness, particular attention is devoted to the effect of segregation and to the underlying social control mechanisms. Effects of temporal embeddedness are examined in a wider study (Takács 2002).

The next section provides a critical survey of previous research on intergroup conflict. It is argued that previous theories neglected the free rider problem that is present within the groups and the social dilemma nature of intergroup competition. This is followed by the introduction of a game theoretical approach that takes into account both within group and intergroup interdependencies. Subsequently, model refinements are presented for the particular case of harmful intergroup conflicts. The section afterwards incorporates structural embeddedness into the game theoretical model and this is the followed by the description of how can intentional individual actions lead to unintended and harmful intergroup fights. The paper is concluded by a discussion that also marks possible directions of subsequent research.

\section{THEORIES OF INTERGROUP CONFLICT AND PEACE: AN OVERVIEW}

\section{Classics and Realistic Conflict Theory}

Classic theories mainly focused on macro explanations and on functional interdependence in intergroup relations. The main concern of the seminal work of Simmel (1955[1908], 1955[1922]) was the functional role of intergroup conflict on cohesion and solidarity within the group. Besides Simmel emphasized that conflict contributes to the integration of the group (Simmel 1955[1908]: 91): “...the group as a whole may enter into an antagonistic relation with a power outside of it, and it is because of this that the tightening of the relations among its members and the intensification of its unity, in consciousness and in action, occur." Simmel also discussed the content of 
interpersonal relationships that drives towards participation in conflict. He argued that individuals have a limited choice in conflict situations, as the force to comply to a uniform action is very strong (Simmel 1955[1908]: 92-93): “A state of conflict ... pulls the members so tightly together and subjects them to such a uniform impulse that they either must completely get along with, or completely repel, one another."

Drawing on the work of Simmel, realistic conflict theory was oriented towards the functions of intergroup conflict (Coser 1968[1956], 1967). As Coser (1968[1956]) claimed, a primary function of conflict is that it establishes and maintains group identities and boundaries. Furthermore it is a basic source of internal solidarity. Besides the functions, the sources of conflict are also of central interest in realistic conflict theory. The starting point of realistic conflict is intergroup competition (Williams 1947; Blumer 1958; Coser 1968[1956]; Sherif 1966a). Groups compete with each other for certain scarce resources and the scarcity of these resources makes intergroup conflict "realistic". Groups try to obtain these resources, because it is in their economic (or any other type of) interest. For instance, religions are in ideological conflict with each other when they claim to be the one and only true religion (Allport 1954). In general, hostility towards the competitive group is just the means for obtaining the scarce resources for the in-group. Hence, groups involved in realistic conflict are in a certain sense rational. Still, this approach has nothing to do with rational individual choice (cf. Coenders, 2001: 14), as it considers the groups as the units of analysis and not the individual members of the groups.

Realistic conflict theory was extended in the individualistic direction by Blalock (1967). Blalock handled actual intergroup competition for scarce resources at the macro level separately from individual actions. In his model, individuals are mobilized if they perceive intergroup competition or an out-group threat. This perception does not necessarily have to coincide with an actual competition (e.g., LeVine and Campbell 1972: 41).

The analysis of Richardson (1948a, 1948b) did not consider the group as the unit of analysis, but was based on statistical proportions of individuals with different moods in the rival groups. His study examined the effect of time on the number of persons in different war-moods in two opposing nations. Richardson explained changes in these numbers by an underlying mechanism that is analogous to epidemics. Friendly and hostile attitudes spread irreversibly as a disease or fashion and result in transitions from one mood to another. When appropriate transition rules and starting parameters are assumed, the typical phases of symmetrical war can be deduced. For certain values of the parameters a balanced state of armament levels is derived. The other two typical scenarios are escalation of a runaway arms race and complete disarmament (Richardson 1951; 1960). However, just like the classical macro-sociological theories, these derivations fail to reveal the micro foundations of intergroup conflict and peace.

\section{Major Directions in Social Psychology}

Individuals and cognitive interdependencies are the focus of theories about intergroup conflict and attitudes in social psychology. On the other hand, these theories tend to neglect the importance of functional interdependencies between the groups that is at least recognized by macro-sociological approaches. 
The positive association between positive attitudes toward in-group members and negative attitudes toward out-group members is emphasized by the theoretical concept of ethnocentrism (Sumner 1974[1906]; LeVine and Campbell 1972; Brewer 1981). Sumner (1974[1906]) claimed that this association is universal and every group has a syndrome of ethnocentrism. In this respect, there is sufficient supporting evidence in the empirical literature, for instance, the studies of urban gangs (Suttles 1967; Jankowski 1991: 88).

Sherif in his "theory of conflict" focused on the emergence of negative out-group attitudes and intergroup hostility (Sherif 1966b; Sherif and Sherif 1969). In line with realistic conflict theory, he emphasized that competitions between groups have a fundamental impact on the evolution of group structures, on negative out-group attitudes, and on the emergence of hostile behavior (Sherif 1966a, 1966b). In his field experiments in a young boys' summer camp, he showed how sport competitions and segregation led to a greater distance between the groups, to prejudice, and even to occasional hostilities (Sherif 1966b). Sherif also attempted to find possible resolutions of conflict. Contact between members of the groups that does not involve interdependence among them did not improve intergroup relations; occasional meetings just provided a place for hostile behavior and clashes. On the other hand, the establishment of super-ordinate, common goals fairly improved the situation. As groups faced a series of cooperative interdependencies, hostilities were disappearing (Sherif 1966b; Brewer 1996a).

For the emergence of in-group favoritism and out-group hostility it is not required that groups are organized or have an established set of norms. In the pursuit of minimal conditions that are sufficient to facilitate intergroup conflict, Tajfel and his colleagues conducted a series of minimal group experiments (Tajfel 1970; Tajfel et al. 1971; Billig and Tajfel 1973). In these experiments, there was no social interaction between the subjects, furthermore the groups were created on a cognitive basis and therefore they are referred to as "minimal". Categorization based on the estimation of the number of dots in a drawing or on the preferences for the paintings of Klee and Kandinsky was already sufficient for the emergence of in-group favoritism. Besides this highly influential result, a pragmatic value of minimal group experiments was that they were able to distinguish and control for different effects, unlike field experiments, where it is also difficult and partly unethical to create "real" social groups.

The minimal group experiments stimulated the formation of social identity theory (Tajfel 1981, 1982; Tajfel and Turner 1986). The basic premise of social identity theory is that individuals strive to achieve or maintain a satisfactory image about them and an important aspect of self-definition is group identification. Social identity is primarily relational and comparative in nature as it is based on intergroup comparison. The polarization of the noble in-group image and the evil out-group picture provides positive social identity. The need for positive psychological group distinctiveness can be achieved through social comparison. intergroup competition provides this comparison, which explains the emergence of in-group favoritism. Individuals invest emotional energy to develop social identity and this might be the basis of their behavioral decision to participate in actions of the in-group. In these cases social identity is not taken into account purposefully, however the strive for social identity can indirectly explain why group members are mobilized (cf. Macy 1997).

Review of Sociology 9 (2003) 
The follow-up of social identity theory has taken different routes. On one side, self-categorization theory emphasized intergroup behavior in terms of underlying cognitive representations. Radical views expressed that individuals are "transformed into groups" via the process of self-categorization (Hogg and Abrams 1988: 21), meaning that this cognitive mechanism is sufficient for thinking in group terms. On the other side, critical remarks maintain that social identity is obtained conditionally, only if the group is seen as an acting social unit (Horwitz and Rabbie 1982). This approach gives more attention to the instrumental character of intergroup relations in which one group competes with another group to achieve valued goals (Rabbie 1982). Some critics in political science argue that the establishment of group identity might have no negative effect at all on the other group. An example is the distinction between the concept of "healthy" patriotism and harmful chauvinism at Kosterman and Feshbach (1989).

These approaches in social psychology emphasized the role of cognitive interdependencies in intergroup relations. On the other hand, they disregarded macro relations between the groups and functional and structural interdependencies (for this categorization, see Lindenberg 1997).

\section{Research Traditions in Microsociology and Economics}

The individualistic perspective of social psychology and the emphasis on functional and structural interdependencies between and within the groups is combined in some theories in micro-sociology and economics. These research directions are most essential for this study, as it intends to explore the micro foundations of intergroup conflict with only a side interest in analyzing cognitive interdependencies.

Segregation and its evolution were the focus of some pioneer models in rational choice sociology. Models of Schelling (1971, 1978) and Esser (1986) have demonstrated how residential segregation can evolve as an unintended result of intentional individual action. These models, however, concentrated on neighborhood preferences as a source of segregation and they did not specify what was wrong with segregation and how it was related to intergroup relations.

Economic incentives are emphasized in intergroup relations by ethnic competition theory (Gellner 1983; Olzak 1986, 1992). Ethnic groups are considered as effective coalitions that are formed to extract material benefits from others or to defend possessions. This is also the source of ethnic competition and violence. The stronger the ethnic competition, the more severe the attitudes towards the competitor group are (Olzak 1986). A core hypothesis is that ethnic collective action is intensified by desegregation of the labor market, as employment possibilities are scarce and they are also the targets of ethnic competition (Olzak 1992: 3). Ethnic groups (and also other groups), however, have fixed group boundaries and membership is not a question of choice. As entry and exit is blocked, ethnic networks enjoy several advantages, like trust, cohesion, and easier establishment of collective action (Wintrobe 1995).

A substantial element of intergroup relations that was neglected by all models discussed so far is the free rider problem present within the groups. Either looking at 
civil war, violence between football supporters, or fights between urban gangs, participation in conflict involves high costs and risk for the participants. Individuals have to sacrifice time and sometimes money to take part. They can have serious injuries and might even risk their lives. If they do not participate and leave others "doing the job", they can still enjoy the benefits. Benefits of intergroup competition (for instance, public happiness, pride, or social identity) can be considered as group public goods, because there is no rivalry in consumption and no group member can be excluded from the consumption. This is the reason why individuals are able to free ride on the effort of others and the within group interdependency can be considered as a collective action problem. Individual contributions are costly, therefore group beneficial collective action is difficult to achieve. The free rider problem that means a contradiction between individual and collective interests is modeled by social dilemma games, including the Prisoner's Dilemma (Rapoport and Chammah 1965; Axelrod 1984; Poundstone 1992). Considering the wide range of societal applications, it is no surprise that for the study of individual behavior in these situations a new research field has evolved (e.g.,, Dawes 1980; Liebrand 1983; van Lange et al. 1992; Kollock 1998). Social dilemma research uses game theory because it provides an adequate model for the interdependence of actions and not due to its key assumption of rationality (Macy 1991: 810).

The presence of the free rider problem in intergroup relations is emphasized by recent models of Fearon and Laitin (1996), Gould (1999), and Bhavnani and Backer (2000). These models also recognize that ways of resolving intergroup conflict are difficult to find, if explanations are only provided for conflict and not for intergroup (interethnic) peace. Furthermore, individuals have contradicting interests considering intergroup and within-group relations. Conflict between the groups often originates from an establishment of an in-group collective action (Gould 1999; Bhavnani and Backer 2000). Successful mobilization within the group is difficult to achieve; violent competitions are therefore less frequent than peaceful coexistence.

This research path will be followed in this study. In order to explain the emergence of intergroup conflict and peace, an explanation for individual participation in conflict will be developed. For this purpose, the theoretical model will be based on the team games approach that considers strategic interdependence of individual actions both in the intergroup context and within the group. In this way, this research diverts from explanations of group conflict that disregarded the purposefulness of individual action and also from studies that failed to recognize the conflict between individual and group interests. The subsequent section provides an introduction to this approach.

\section{THE TEAM GAMES APPROACH}

The theories introduced in the previous section are all lacking one or more important aspects that an adequate theory on intergroup conflict should have. First of all, groups cannot be handled as unitary entities as they consist of consciously acting individuals who primarily care about their own gains and losses. The most challenging

Review of Sociology 9 (2003) 
problem for research is when intergroup conflict is an aggregated outcome of voluntary and intentional individual actions. The theoretical foundations of the modeling framework should take this into consideration. The appropriate model should represent the duality of within-group and intergroup interdependencies. Furthermore, the explanation of intergroup conflict should start from a simple and abstract theoretical model (Lindenberg 1992).

Considering within group interdependency as a collective action problem is one key element in the model of intergroup relations. Another key element that makes intergroup conflict different from other collective action problems is the interdependence between the groups. As it was suggested first by realistic conflict theory (see previous section), the origin of intergroup conflict is that the groups compete for obtaining certain scarce resources. Examples of such resources are territory or economic control. However, intergroup competition can also be heated by immaterial benefits, like pride, avoidance of shame, or social identity. Benefits to football hooligans are certainly only immaterial and consists of, for instance, the pride of being the most feared ultras. As an immaterial benefit that exists only in intergroup relations, the striving for social identity can explain group-beneficial behavior in minimal groups (Tajeel 1970). It can also provide a reason for why groups are more competitive and aggressive than individuals (cf. Kramer and Brewer 1984, 1986; Tajfel and Turner 1986), which is referred to as the discontinuity effect (Schopler and Insko 1992; Insko et al. 1993, 1994). Experiments also confirmed that when they are playing alone and when they are members of groups, individuals behave differently (Bornstein, Erev and Rosen 1990; Schopler and Insko 1992; Insko et al. 1994; Bornstein and Ben-Yossef 1994). Subjects were more inclined to make sacrifices for their group to win from another group than they were for themselves in two-person situations. ${ }^{2}$

Which group is able to realize the benefits of intergroup competition depends on an intergroup comparison of strength and efficiency of mobilization of group members. Practically, one of the major determinants is the number of people mobilized. Meanwhile the winning group obtains the benefits, the other group can suffer from negative consequences (for instance, loss of resources, shame, humiliation). For instance, successful recruitment of volunteers into paramilitary units creates possible gains for the in-group, but certainly hurts the interests of the out-group. Both sides are punished in the case of mobilization of a similar strength. Endless civil war, unsettled disputes, mutually harmful clashes are such examples where no benefits are realized. These outcomes are worse for everyone compared to no mobilization and peace.

This character of intergroup interdependence resembles the two-person Prisoner's Dilemma (e.g., Rapoport and Chammah 1965; Axelrod 1984; Poundstone 1992). If groups were unitary entities and they could choose between mobilization and no mobilization, mobilization would be their dominant strategy. This means that regardless of the action of the out-group, the in-group would gain more with mobilization. Following the dominant strategy by both sides would result in a sub-optimal outcome.

2 As a referee noted, an alternative explanation could make use of Durkheim's notion of collective consciousness. Participation in intergroup conflict may contribute to emotional vitality, but fighting a person in a dyadic situation does not produce such a vitality. Incorporating this concept to individual considerations, however, would produce that harmful intergroup conflict is the desired consequence of individual actions, which is most often not the case. 
However, groups do not fight with each other in every situation. They are often unable to establish collective action because of ramifying interests within the group. This way, within group interdependencies can help to solve conflicts between the groups. Hence, there are two different perspectives of the situation. On one hand, conflicts between groups can be resolved by interdependencies within the groups. On the other hand, intergroup competition can be considered as a possible structural solution to social dilemmas within the group (Bornstein, Erev and Rosen 1990; Erev et al. 1993). To summarize, the model of intergroup competition should capture this duality of within-group and intergroup interdependencies and should represent the mixed motives of individual decisions.

Until now, however, theories of group conflict hardly made any connection to collective action problems within the groups and theories of collective action overlooked intergroup relations. A framework that would allow for a combined modeling is offered by the team games approach (Palfrey and Rosenthal 1983; Rapoport and Bornstein 1987). In team games, competitive group relations are represented by a game. There are two levels of the game. At the intergroup level, groups as aggregates face an interdependent situation. Group action is determined as a consequence of individual actions within the group. Individuals decide either to contribute to the group action (make a sacrifice for their group) or not. ${ }^{3}$ Individual decisions are strategically interdependent, which is represented as $n$-person games at the within-group level.

In the intergroup Prisoner's Dilemma (IPD) game (Bornstein 1992; Insko et al. 1994; Bornstein et al. 1996; Goren and Bornstein 2000) individuals are always better off when they do not participate in the group action. Public rewards for group-members increase with the difference between the number of participants in the own group and in the other group. Besides, if the numbers of participants are equal, higher rewards are distributed, in case more people are mobilized. In this game, no participation is a dominant strategy equilibrium that is sub-optimal in comparison to the outcome in which everyone participates.

Similarly, in the intergroup Public Goods (IPG) game (Rapoport and Bornstein 1987; Bornstein 1992) intergroup competition is based on the number of contributors. Public good benefits are distributed in the group with more contributors. In case the numbers of contributors are equal, scarce public good rewards are divided between the groups. In the IPG game, individuals do not have a dominant strategy, since there are situations in which a single decision changes the result of the competition. Still, in most cases, not contributing is a more beneficial option.

On one hand, the IPG game nicely represents the dichotomy of interdependencies within the groups (provision of a public good) and between the groups (intergroup competition). On the other hand, the IPD game can illustrate the social trap character of harmful intergroup competitions. If both groups are able to mobilize their members effectively, the result of the competition is harmful for both sides. A modification of the IPG game with this character would result in a model that describes more closely lethal intergroup conflicts.

3 In several intergroup competitions individual decisions are not binary, but continuous (for instance, how accurately warriors shoot in civil war).

Review of Sociology 9 (2003) 


\section{THE INTERGROUP PUBLIC GOODS (IPG) GAME WITH CLASH PUNISHMENT}

In this section, a new model will be presented that meets the requirements of the previous sections. There are two exclusive groups $A$ and $B$ of size $n_{A}$ and $n_{B}\left(n_{A} \geq 2\right.$ and $n_{B} \geq 2$ ), with contradictory collective interests. Inside both groups, members face the dilemma of providing a step-level public good (cf. Bornstein 1992). A step-level public good is only provided, if a certain level of contribution has been reached. This level is determined by the number of contributors in the other group.

Group members are anonymous and can gain (lose) the same rewards from the intergroup context with identical action. For instance, everyone is supposed to be equally proud after a victory and equally ashamed after a defeat. ${ }^{4}$ If the number of contributors in group $A$ exceeds the number of contributors in group $B$, then each member in $A$ receives a reward $v$ (a piece of a victory-cake, temptation reward) and members of $B$ receive a reward of $d$ (defeat, the sucker's payoff). If the number of contributors is equal, then everyone receives a reward $c$ (clash, reward for a draw). These rewards are independent of group size and the relation between them is $v>c>d$. As an example, consider a team sport in which members of the two teams decide whether they help their team with low or high effort. High effort can be regarded as contribution to the provision of the public good that is a win in the competition. Figure 1 provides a graphic illustration about the outcomes of the game.

A free riding action (low effort in the previous example) results in an extra positive reward of $e$ (endowment, $v>e>d$ ). All members of the winning team are happy, but those who contributed with low effort gain more as they preserved their energy for another activity (opportunity cost of contribution). Table 1 represents the payoffs from the IPG game.

As Table 1 shows, the IPG game is not a perfect social dilemma. When $c>d+e$, in state (II) $i$ is better off by contributing and when $v>c+e$, in state (III) contribution is a better choice. Given the lack of a dominant strategy Rapoport and Bornstein (1987) assume that individuals order expected values to the actions and maximize this expected value. Critical probabilities (cf. Caporael et al. 1989) concerning states (II) and (III) show the likelihood that the single individual action of $i$ has an influence on the overall outcome. If group sizes are large, then critical probabilities are small and the structure of the game is close to being a pure in-group social dilemma (cf. Bornstein and Rapoport 1988: 127; Takács 2002). ${ }^{5}$ Inaction therefore is very likely to be the outcome of intergroup opposition (cf. Fearon and Laitin 1996; Gould 1999). Consequently, predictions derived from expected value calculations are in contradiction with the Nash-equilibrium solution of overall contribution (with equal group sizes).

4 For the sake of simplicity, rewards are numerical and individual utility is simply a linear function of rewards. Since no inter-individual comparisons are made, it is enough to assume that everyone values his or her share relatively the same way in comparison to other rewards and costs of him or her.

5 As rewards are independent of group size, this consequence is not "wired in" the assumptions of the model. 


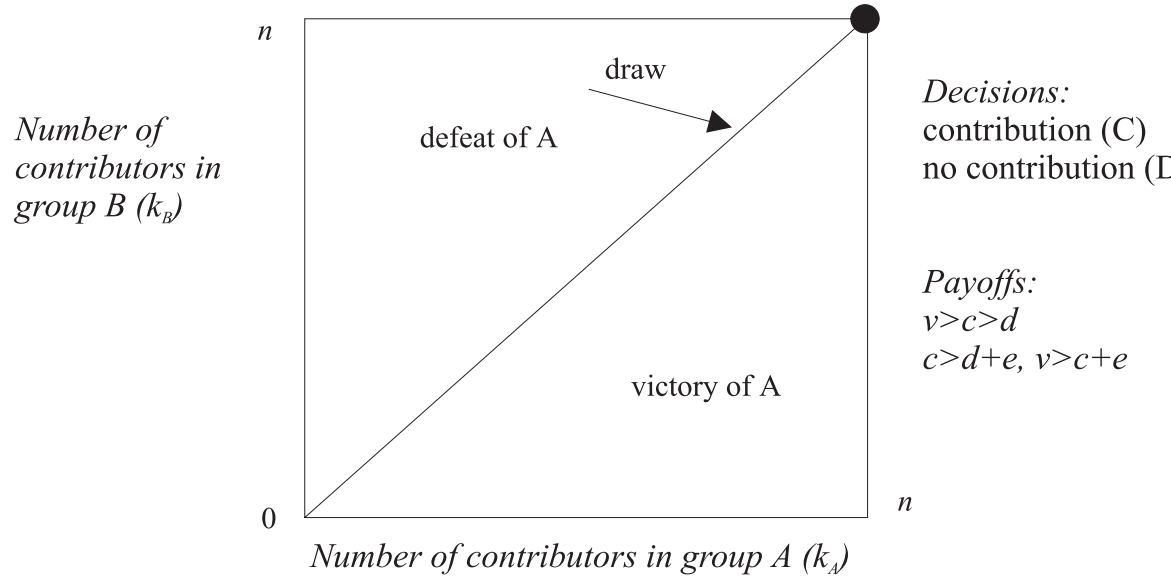

Figure 1. Graphical representation of the outcomes of the IPG game and Nash-equilibrium (bullet)

However, the social trap character of a stalemate is not incorporated in the original IPG model. Therefore, that model can be applied to different intergroup competition situations in which a tied outcome does not have a harmful character. An example is an election in two-party democracies. A tie can be embarrassing and can lead to lengthy and costly recounting and law suites, but it is not worse than if nobody voted. Similarly, in team sports a scoreless draw at a boring match is definitely not better than a draw with many goals, where all players gave their best. Competitions between ethnic groups, urban gangs, or pupil groups have a different character. A draw means a mutually harmful clash that is worse than the lack of collective action (peace). To explain the emergence of such outcomes, modifications are borrowed from the IPD game.

Table 1. Possible payoffs from the IPG game for player $i \in A$

(Rapoport and Bornstein 1987)

\begin{tabular}{|l|c|c|c|c|}
\hline \multicolumn{1}{|c|}{ Outcome } & $\begin{array}{c}\text { (I) } \\
\text { Unconditional } \\
\text { defeat }\end{array}$ & $\begin{array}{c}\text { (II) } \\
\text { One for the draw }\end{array}$ & $\begin{array}{c}\text { (III) } \\
\text { One for the } \\
\text { victory }\end{array}$ & $\begin{array}{c}\text { Unconditional } \\
\text { victory }\end{array}$ \\
\hline Conditions & $k_{A-i}<k_{B-1}$ & $k_{A-i}=k_{B-1}$ & $k_{A-i}=k_{B}$ & $k_{A-i}>k_{B}$ \\
\hline Contribution & $d$ & $c$ & $v$ & $v$ \\
\hline No contribution & $d+e$ & $d+e$ & $c+e$ & $v+e$ \\
\hline
\end{tabular}

Notes: $k_{A-i}=$ the number of contributors in group $A$ (excluding player $i$ ); $k_{B}=$ the number of contributors in group $B$. 
As in empirical conflict situations mutual mobilization significantly differs from mutual lack of mobilization, it should be specified how the payoffs depend on the number of contributors, if contributors in the two groups are equal in number. If a couple of Serb civilians shoot at Bosnian civilians, this would not yet be a civil war situation, but would be treated as an attempt of murder. Ethnic clash starts, if the number of contributors is large enough. For this reason, besides the endogenous threshold (the number of contributors in the other group), this study introduces an exogenous minimal contributing set (MCS) in the game (cf. van de Kragt, Orbell and Dawes 1983). This means that below a specified number of contributors no collective action will be established in the group and consequently provision of the victory and clash for public goods is not possible. Since groups can differ in their internal structure of norms, one group can exhibit a more patient attitude in intergroup relations. Therefore the minimal contributing sets are allowed to be different in the groups and are denoted by $k_{A} *\left(0 \leq k_{A} * \leq n_{A}\right)$ in group $A$ and by $k_{B} *$ $\left(0 \leq k_{B} * \leq n_{B}\right)$ in group $B$.

If the number of contributors is equal and both groups are above the minimal contributing set, then everyone receives a negative reward $c$ (clash, punishment payoff). The clash of collective actions is supposed to be worse than the outcome of peace. Peace is the collective outcome in which no collective action is established in the groups. For the sake of simplicity the reward for peace $p$ is a reference value and assumed to be zero. Hence, the relation between the different payoffs is $v>p=0>c>d$. If groups were unitary entities and they could choose between either collective action or no action, collective action would be their dominant strategy. Both sides following the dominant strategy would lead to a sub-optimal outcome. All outcomes, where collective action is established at least in one of the groups, can be considered as conflicts.

The assumption that a free riding action results in an extra individual reward of $e$ (endowment, $v>e>0$ ) is retained. Table 2 gives a complete typology of possible outcomes of the IPG game and represents the payoffs for player $i \in A$.

The IPG game in this form is intended to model group competition situations in which collective action of equal strength leads to mutually harmful outcomes (clash punishment). Examples are civil war, conflicts between pupil groups, fights between football supporters or urban gangs. In the case of only a few initiators, nothing happens and the status quo is preserved. If, however, the number of contributors exceeds a certain threshold, a collective action is established and this can mean victory for the group. A group wins if more members contributed to the collective action than in the other group. Defeat is the worst-case scenario: just imagine the frustration experienced by gang members having lost a street battle.

Similar to the original IPG game, there is no dominant individual strategy in the modified game. In states III, IV, V, and VI (cf. Table 2) contribution is a better choice. In these states a single individual decision is critical for the outcome. If group sizes are large and the minimal contributing sets are relatively high, then this likelihood is extremely small. Similar to the original IPG game, peace (no collective action) is the expected outcome of intergroup opposition. 
Table 2. Possible payoffs from the IPG game with clash punishment ${ }^{6}$

\begin{tabular}{|c|c|c|c|c|c|c|c|}
\hline & $\begin{array}{c}(\mathrm{I}) \\
\text { Peace }\end{array}$ & $\begin{array}{c}\text { (II) } \\
\text { Un- } \\
\text { conditional } \\
\text { defeat }\end{array}$ & $\begin{array}{l}\text { (III) } \\
\text { One for the } \\
\text { clash }\end{array}$ & $\begin{array}{l}\text { (IV) } \\
\text { One for } \\
\text { MCS }\end{array}$ & $\begin{array}{l}\text { (V) } \\
\text { From } \\
\text { defeat to } \\
\text { victory }\end{array}$ & $\begin{array}{l}(\mathrm{VI}) \\
\text { One for the } \\
\text { victory }\end{array}$ & $\begin{array}{l}\text { (VII) } \\
\text { Un- } \\
\text { conditional } \\
\text { victory }\end{array}$ \\
\hline & $\begin{array}{l}k_{A-i}<k_{A} *-1 \\
\text { and } \\
k_{B}<k_{B} *\end{array}$ & $\begin{array}{l}\left(k_{A-i}<k_{B}-1 \text { or }\right. \\
\left.k_{A-i}<k_{A} *-1\right) \\
\text { and } k_{B} \geq k_{B} *\end{array}$ & $\begin{array}{l}k_{A-i}=k_{B-1} \text { and } \\
k_{B} \geq k_{B} * \text { and } \\
k_{A-i}+1 \geq k_{A} *\end{array}$ & $\begin{array}{l}k_{A-i}=k_{A}{ }^{*}-1 \\
\text { and } k_{B}<k_{B} *\end{array}$ & $\begin{array}{l}k_{A-i}=k_{A} *-1 \geq \\
\geq k_{B} \geq k_{B} *\end{array}$ & $\begin{array}{l}k_{A} * \leq k_{A-i}= \\
=k_{B} \geq k_{B} *\end{array}$ & $\begin{array}{l}\left(k_{A-i}>k_{B} \text { or }\right. \\
\left.k_{B}<k_{B} *\right) \text { and } \\
k_{A-i} \geq k_{A} *\end{array}$ \\
\hline $\mathrm{C}$ & 0 & $d$ & $c$ & $v$ & $v$ & $v$ & $v$ \\
\hline D & $e$ & $d+e$ & $d+e$ & $e$ & $d+e$ & $c+e$ & $v+e$ \\
\hline
\end{tabular}

Notes: $k_{A-i}=$ the number of contributors in group $A$ (excluding player $i$ ); $k_{B}=$ the number of contributors in group $B$.

A specific example of the game is represented graphically in Figure 2. In this example group sizes and the minimal contributing sets are equal. Bullets indicate Nash equilibria. In general (if minimal contributing sets are larger than one), pure strategy Nash equilibria are the situations in which there are $\{0 ; 0\},\left\{k_{\mathrm{A}}^{*} ; 0\right\}$, or $\left\{0 ; k_{\mathrm{B}}{ }^{*}\right\}$ contributors. Overall defection is equilibrium, because a single contribution cannot break the peace, but involves the loss of endowment $e$. Another Nash equilibrium is when the number of contributors in one group equals to the MCS and in the other group there are no contributors. In this case, no contributor would be better off by free riding, because $v>e$. For defectors, it would not make sense to change their decisions, because they cannot improve on the outcome alone. In addition to these equilibria, clash with overall participation is also a Nash equilibrium, if group sizes are equal and $d+e<c$. This equilibrium is never Pareto-optimal.

6 State $(\mathrm{V})$ is the exceptional case and only relevant if $k_{A}{ }^{*}>k_{B}{ }^{*}$. In this state there are an equal number of contributors in both groups. Collective action is established only in group $B$, but the contribution of player $i \in A$ means that the outcome is victory of group $A$. State (I) is not relevant, where less than two contributors can establish group collective action and state (IV) is not relevant, where the minimal contributing sets are zero. States (VI) and (VII) are irrelevant, if $k_{A}{ }^{*}=n_{A}$

Review of Sociology 9 (2003) 


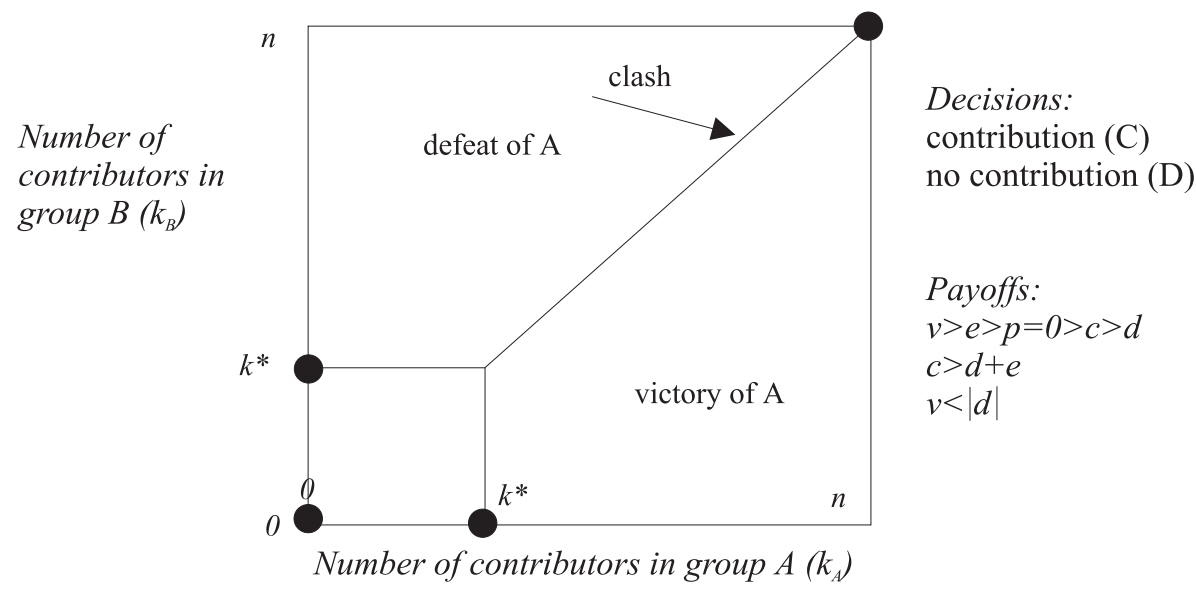

Figure 2. Graphical representation of an example of the IPG game with clash punishment and Nash equilibria (bullets)

\section{STRUCTURAL EMBEDDEDNESS OF ACTIONS}

In the previous sections, the team games approach was introduced as a model of intergroup relations. Team games, however, completely disregard the structural embeddedness of individual actions. Behavior is embedded structurally, as everyone's behavior is to a large extent constrained by neighbors, friends, colleagues, and the family, regardless of group affiliations. Not only the team games approach, but also other prominent theories of intergroup conflict neglected the role of interpersonal relations. As the main interest of this study is in the explanation of intergroup conflict and peace, the model has to be extended, as it needs to deal with behavioral constraints and influences of social networks.

With regard to interpersonal contact and interaction between members of the opposite groups, the contact hypothesis of Allport (1954) suggested that these are crucial to preserve good intergroup relations. In the presence of extensive interpersonal ties across group borders, the emergence of negative attitudes towards the out-group would be less likely. The contact hypothesis indirectly implies an increasing effect of segregation on the likelihood of intergroup conflicts. Supportive findings in empirical research showed highest intolerance and most competitive intergroup attitudes in homogenous ethnic enclaves (Anderson 1983; Denitch 1994; Massey et al. 1999). Although contact across group borders seems to be the key to the reduction of intergroup conflict, it works only conditional on the quality, frequency, and extensiveness of the contact and on the context in which it takes place (Brewer and Miller 1984, 1996: 132; Brewer 1996a, 1996b, 1999).

Interpersonal ties between members of the same group also influence the outcome of intergroup competition. As intergroup conflict involves collective action problems within the groups, this study might build on the recommendations of research about 
social network effects in collective action situations. It is widely believed that dense in-group relations help the establishment of collective action (Marwell et al. 1988; Coleman 1990: 318-320; Marwell and Oliver 1993: 102; Gould 1993; Opp and Gern 1993).

As social networks are known to greatly affect behavior in collective action situations, it is quite surprising that there is almost a complete lack of research that addresses social network effects and the underlying micro mechanisms in intergroup conflict. The main drawback of empirical studies is that they are purely descriptive and they do not test micro processes of social network effects and in particular, of segregation effects. On the other hand, empirical results show that segregation can be associated with higher likelihood of intergroup conflict (Blau and Schwartz 1984; Whyte 1986; Diez Medrano 1994; Olzak et al. 1996).

Explanations of intergroup conflict should not be satisfied with discovering merely associations between social network properties and intergroup conflict. For a deeper understanding, underlying mechanisms of social network effects should be revealed. As these mechanisms work at the interpersonal level, the role of social contacts and their influence on participation decisions in intergroup competition should be specified.

A concept that embraces a wide range of micro mechanisms and specifies the content of dyadic interdependencies is social control (Heckathorn 1990, 1993; Macy 1993). Social control is defined as a constraint on individual decision posed by the influence as well as the presence, opinion, expectations, and behavior of relevant other individuals (cf. Villareal 2002).

This study concentrates on three different social control mechanisms. Social control in these forms constrains individual action by creating positive and negative incentives. First, the close social environment is a source of distribution of selective incentives, including social norms (Sandell and Stern 1998). Durkheim (1984[1893]) and Parsons (1937), well before the rise of social dilemma research, have claimed that social norms help to solve the conflict between individual goals and common interest in favor of collective goals. The concept of selective incentives originates from Olson (1965), who showed the conditions under which the provision of selective incentives solves social dilemmas in a world of rational actors. Selective incentives from group fellows help the establishment of collective action as they reward participation and punish free riders within the group (Olson 1965). The provision of these incentives is completely dependent on choices made in the intergroup context and does not require separate decisions. Therefore, it is more appropriate to consider them as additional incentives rather than produced normatives that raise a second order free rider problem (cf. Heckathorn 1989).

Second, behavior is constrained by social control as individuals strive for behavioral confirmation (Lindenberg 1986). Behavioral confirmation is received for an action that is identical to behavior of related individuals. Finkel and Opp (1991) have found that participation in collective political action can be largely explained by willingness to conform to the expectations of important others. Furthermore, empirical evidence shows that people do not participate in collective actions in isolation, but together with friends and neighbors (see McAdam 1986; Gould 1991; Opp and Gern

Review of Sociology 9 (2003) 
1993). Individuals decide to participate, if they are assured of the participation of their friends (Chong 1991; Oberschall 1973, 1994). Chong (1991) and Oberschall (1994) described this as an assurance process. In the assurance process, behavioral confirmation has a two-fold effect. Confirmation by participating fellows provides an incentive for contribution and confirmation by free riders works against contribution.

Third, in intergroup relations, ties that connect members of the opposite groups pose a different constraint to individual behavior. Friends from competing groups have contradictory interests in the intergroup context. Since their friendship is valuable for them, they reward the other's action that is against the own group's interest (e.g., Kuran 1995: 9-10). For instance, supporters surrounded by fans of the other club are esteemed for traitor behavior and for remaining silent, if their team scores.

In short, three different forms of social control that are transmitted by network ties will be incorporated in the model of intergroup conflict. These are traitor rewards, behavioral confirmation, and social selective incentives. As a result of dyadic social control, individuals can be mobilized to participate in collective action that has harmful consequences in the intergroup context.

If their neighbors or friends are from the other group, individuals are rewarded for not participating in the collective action. Assume that everyone receives a $t>0$ traitor reward in the case of no contribution for each tie that connects this person to members of the opposite group. Hence the traitor payoff is a selective incentive rewarding defection and distributed locally conditional on the number of ties with the other group. The traitor reward provides an additional incentive for people, who live close to members of the opposite group, to restrain from participation in collective action.

Ties connecting members of the same group transmit different social incentives. People receive behavioral confirmation $(b>0)$ from each relation by acting similarly to their fellow friends. This reward is a mutual positive externality, which drives towards uniform action. Irrespective of behavioral confirmation, contribution is rewarded by fellow neighbors or friends. They appreciate group-beneficial action by social selective incentives. All contributors receive a selective incentive $s>0$ from each fellow neighbor. The provision of these incentives does not require separate decisions as they always accompany choices made in the intergroup game. This assumption is plausible for certain social rewards such as respect or status that can be by-products of intergroup relations. The relationship between fellow neighbors or friends can be represented as a local coordination game (see Table 3). ${ }^{7}$ Unlike public goods ("bads") $v, c$ and $d$, bestowing the three types of social incentives is not conditional on the outcome of the intergroup competition.

The structurally embedded IPG game is the extension of the IPG game (Table 2 and Figure 2) with the incentives $(t, b$, and $s)$ from the network environment. Individuals must choose a single action (contribution or no contribution) and cannot tailor their behavior to each neighbor. ${ }^{8}$

7 For the sake of simplicity, selective incentives and confirmation payoffs are held constant through all pair wise games. It is sufficient to assume, however, that all individuals relate social rewards to other rewards and costs in the same way.

8 It is also the assumption of the literature on local interaction games (see Morris 2000: 57). 
Table 3. Local coordination game between fellow neighbors

\begin{tabular}{|l|l|c|c|}
\hline \multicolumn{2}{|c|}{} & \multicolumn{2}{|c|}{ Neighbor from the same group } \\
\cline { 2 - 4 } & contribute & do not contribute \\
\hline \multirow{3}{*}{ individual $i$} & contribute & $b+s, b+s$ & $s, 0$ \\
\cline { 2 - 4 } & do not contribute & $0, s$ & $b, b$ \\
\hline
\end{tabular}

\section{THE SOCIAL DILEMMA OF CONFLICT: PROBLEMS WITH CONTRIBUTION}

In the structurally embedded IPG game, no contribution is the dominant strategy of player $i \in A$, if defection provides higher rewards than contributing even if all fellow neighbors are contributing and a single additional contribution would change the outcome of the game. That is, defection is a dominant strategy of player $i \in A$, if ${ }^{9}$

$$
g_{i} t+e>f_{i}(s+b)+v-d,
$$

where $f_{i}$ denotes the number of fellow neighbors of $i$ and $g_{i}$ stands for the number of neighbors from group $B$.

At the other extreme, contribution can also be a dominant strategy. For this, selective incentives have to exceed rewards for defection in the "worst case" scenario, i.e. when no fellow neighbors are contributing and a single contribution does not change the outcome. That is, contribution is a dominant strategy of player $i \in A$, if

$$
g_{i} t+e<f_{i}(s-b)
$$

Although the decision of $i$ is not likely to be critical, contribution can be highly beneficial due to social incentives. For instance, many individuals join tribal wars although the gains from these conflicts are only symbolic and single contributions make no difference. One reason is that warriors can attain high status in the group and can easily become "heroes". A similar argument can be used to explain redundant contribution choice (Caporael et al. 1989). People seek social rewards when they sacrifice their contribution to the production of a public good that has already been established.

Nash equilibria in the structurally embedded game can be very different from the original IPG game, depending on the exact network structure. Social networks decisively shape conditions under which social incentives can generate solutions for

9 If ${k_{B}}^{*} \geq k_{A}{ }^{*}$, then the less strict conditions $g_{i} t+e>f_{i}(s+b)+c-d$

and

$g_{i} t+e>f_{i}(s+b)+v-c$

are sufficient to hold for defection (no contribution) to be a dominant strategy.

Review of Sociology 9 (2003) 
the in-group collective action problem. In a highly segregated network with dense in-group and scarce out-group relations overall participation is likely to be in equilibrium. Full contribution can be dominant strategy equilibrium and a sub-optimal outcome in which every individual payoff is smaller than in overall peace. The unusual social dilemma that traps groups in harmful contribution emerges, if

$$
|c|>f_{i} s-g_{i} t-e>f_{i} b
$$

holds for every individual.

In most cases, however, there is no dominant strategy equilibrium in the structurally embedded IPG game. In these situations, auxiliary assumptions are necessary on individual behavior to derive predictions about the outcome of intergroup competition. How these assumptions are formulated depends on the conceptual view about individual decision-making that is very much debated in the social science disciplines. To circumvent this problem, a previous study (Takács 2001) derived model predictions under four conditions that were different in the assumptions about the level of rational consciousness individuals have.

Simulation results showed that segregation has a crucial effect on the expected likelihood of conflict when selective incentives are strong compared to behavioral confirmation. If contribution can be a dominant strategy $(s>b)$, then the relationship between segregation and the expected likelihood of conflict is best described by a steep S-shape curve. However, depending on other parameter values, in certain ranges of segregation, an additional change does not result in an increase in the likelihood of conflict. These cases were labeled as floor and ceiling effects. In general, the segregation effect somewhat increases, as more rigid behavioral assumptions are applied. However, curves only become slightly steeper. This implies that assumptions on individual consciousness and local information are not crucial to determine segregation effects on conflict (cf. Takács 2001).

However, in some specific structures more rigid assumptions on rationality definitely change predictions. This is because segregation is not the only network characteristic that influences the likelihood of conflict between groups. For instance, minority hostages can suppress mobilization, bridging ties can play a brokerage in the spread of contribution, and loosely connected subgroups may either elicit or inhibit intergroup conflict depending on the behavioral assumptions (cf. Takács 2001). As a practical implication for residential policy, it is often more efficient to place certain persons to the right position than to implement a costly wide-range desegregation policy. A presence of a small minority in an otherwise homogenous environment might be sufficient to excite sympathy for the rival group and to suppress activism. Bridging ties between isolated subgroups might play a crucial role in the dissemination of radical, but also of peaceful attitudes. Takács (2001) illustrated that one gatekeeper is usually not enough to play such a brokerage. Multiple bridging ties do this better, when supported by strong bridgeheads that is by influential group members, who are in contact with the intermediary persons. To keep hawkish tendencies at a low level, the most efficient way is to close down the radical groups' bridging contacts to the outside world, and thus to isolate radicalism. With regard to the question of how can such 
structural strategies be implemented in practice, one can benefit from recommendations of applied social network analysis (e.g., Kratzer, 2001; Leenders et al. 2002).

\section{DISCUSSION}

The aim of this paper was to review the existing literature on intergroup conflict, and by learning from their strong and weak aspects, to construct a theoretical model of intergroup conflict that is based on the interdependency of individual decisions and integrates sociological insight into the analysis. The latter was achieved by focusing on social control mechanisms that, besides the rewards from the intergroup context, influence individual decisions. Forms of social control are transmitted through network ties; consequently the network structure has a strong impact on the emergence of intergroup conflicts.

Previous research found that intergroup competition, the local assurance process, and the application of selective incentives are possible structural solutions to social dilemmas. By integrating these different ideas in a general model, this study showed that a different social dilemma might occur in which overall contribution traps the groups in a mutually harmful outcome. The study also paid attention to structural conditions that can help to avoid lethal conflicts. In particular, results indicate that segregation is likely to increase the likelihood of conflict when selective incentives are more important than the confirmation pressure of relevant fellows.

The model introduced by this study was built on the presumption that the origin of intergroup conflict is the competition between the groups for certain limited resources. If there is no competition, intergroup relations have a completely different nature. In most cases, the lack of negative interdependency is a guarantee for peaceful coexistence, even if there is a high level of segregation. In these situations, there could be other difficulties, such as coordination problems. For instance, using the same standards would be beneficial for interacting groups, but naturally enough, none of the groups are keen on changing its own established system. This study has not dealt with such situations, but it might have some valid implications also for these cases. The underlying mechanisms of social control and decision heuristics work in a similar way in these contexts, causing effects of structural embeddedness. For example, people experience strong confirmation pressure from relevant others to use identical standards, such as speaking the same language as they speak. Consequently, members of a minority, who are exposed to members of the majority group, are easily forced to adopt the standards of the other group. Furthermore, segregation of the social network directly leads to the same standards within the segments, such as to the evolution of dialects in remote parts of a language area.

A closer correspondence can be made between the results of this study and situations in which groups actually compete for a certain goal. However, not all competitions are social dilemmas, as mutual collective action does not always have sub-optimal consequences. intergroup rivalry might result in a draw that is not harmful for either side or the groups may reach a compromise and divide the public good.

Review of Sociology 9 (2003) 
Furthermore, competitions might have a positive value for the larger community such as in the case of team sports or competition between R\&D teams. In these cases, there is still a free riding problem within the groups, but mobilization has positive externalities for the other group. The community has an interest in enforcing participation. Therefore policy suggestions that follow from this analysis are the opposite to the case of harmful competition. In order to facilitate contribution, dense relations within the group and strong selective incentives are needed. Besides, ties between members of the rival groups should be minimized or should be kept at a neutral level.

These implications also hold for in-group collective action problems. The key mechanism to the solution of these social dilemmas is the distribution of strong selective incentives and their internalization. The model presented in this study predicts, similarly to Coleman (1990), that this works best in a dense network with transitive ties. On the other hand, strong confirmation pressure in a dense network might lead to widespread contribution as well as to overall defection. In this way, behavioral confirmation is double edged for cooperation, just as in the case of approval exchange (Flache 1996).

There are possibly many more situations, to which the results of this study can be implied. However, the major goal of this research was to understand and explain the emergence of mutually harmful intergroup conflict situations and to show under which conditions these can be avoided. In this respect, the major contribution of this study was to reveal mechanisms that explain how and why conflicts emerge as a result of structural embeddedness of individual actions.

In relation to structural embeddedness, the major conclusion of the study is that segregation is likely to promote intergroup conflict. Starting from a certain structural configuration, an increase in the number of relations within the group or a decrease in the number of relations toward members of the other group will not facilitate conflict resolution. For instance, this result supports policy arguments to encourage interethnic relations and decrease residential segregation in order to help the resolution of ethnic conflicts. Theoretical results suggest, however, that such a policy will not always be effective. Conflict can just as likely occur in middle ranges of clustering as it can in the completely segregated setup, due to weak traitor incentives and the strong influence of (internalized) fellow pressure (cf. Takács 2002). Furthermore, already a few zealots might be sufficient to initiate conflict even in a relatively mixed configuration. In these cases, especially if the costs of desegregation are high, it is better to seek institutional or external solutions for the management of damaging intergroup relations. Furthermore, desegregation policies also have to be aware of other influential network properties.

Possible applications of the model include ethnic conflict in neighborhoods, villages, or cities under different residential structures; conflict between football supporters in a stadium or between pupils in a classroom under different seating patterns; and participation in voting in two-party democracies. Empirical evidence from different areas provides support for many of the model predictions. For instance, residential segregation and separate education was found highly responsible for repeated conflict in Northern Ireland (Whyte 1986). In studies of voting behavior, the 
classical work of Tingsten (1963 [1937]) has shown that socialist party choice is disproportionately more likely in working class districts. Further evidence of a nonlinearly increasing effect of segregation on voting was found by Butler and Stokes (1974) and Ragin (1986).

On the other hand, there is a valid concern about the limited applicability of the model to empirical situations. The ecological validity would be enhanced significantly if some of the parameter values were based on empirical data. However, the measurement of payoff parameters (especially social selective incentives and behavioral confirmation) is highly problematic. Numeration of public good rewards (e.g., social identity and nationalist pride) is also often impossible. Furthermore, the model is based on far too simple assumptions to be sufficiently competent to describe the complexity of reality.

The focus on single-shot games results in the neglect of time. In the model, simultaneous actions of individuals are assumed, although in many empirical situations there are long-term delays and people can obtain information about the decision of others. More strikingly, the history of intergroup relations was disregarded, which is the root of many empirical conflict situations. Issues of history and temporal embeddedness in general are discussed in detail by Takács (2002).

Individual differences of many forms can also be incorporated in advanced model building. Examples are the possible distinctions between leaders and followers (asymmetric neighborhood games), aggressive and peaceful players or social and egoistic types (with different perceptions about the relations between payoff parameters). Payoff restrictions of the present model (e.g., zero reward for peace) can be easily relaxed. Besides these possible developments, a major proceeding can constitute a dynamic model, in which the feedback effect of conflict is incorporated on the residential structure.

\section{REFERENCES}

Allport, G.W. (1954): The Nature of Prejudice. Reading, MA: Addison-Wesley.

Anderson, B. (1983): Imagined Communities. New York: Verso.

Axelrod, R. (1984): The Evolution of Cooperation. New York: Basic Books.

Bhavnani, R. and Backer, D. (2000): Localized Ethnic Conflict and Genocide. Accounting for Differences in Rwanda and Burundi. Journal of Conflict Resolution, 44(3): 283-306.

Billig, M.G. and Tajfel, H. (1973): Social Categorization and Similarity in intergroup Behaviour. European Journal of Social Psychology, 3: 27-52.

Blalock, H.M. (1967): Toward a Theory of Minority-Group Relations. New York: Wiley.

Blau, P.M. and Schwartz, J.E. (1984): Crosscutting Social Circles. Testing a Macrostructural Theory of intergroup Relations. Orlando: Academic Press.

Blumer, H. (1958): Race Prejudice as a Sense of Group Position. Pacific Sociological Review, 1(1): $3-7$.

Bornstein, G. (1992): The Free-Rider Problem in intergroup Conflicts over Step-Level and Continuous Public Goods. Journal of Personality and Social Psychology, 62: 597-606.

Bornstein, G. and Ben-Yossef, M. (1994): Cooperation in intergroup and Single-Group Social Dilemmas. Journal of Experimental Social Psychology, 30: 52-67.

Review of Sociology 9 (2003) 
Bornstein, G.; Erev, I. and Rosen, O. (1990): intergroup Competition as a Structural Solution to Social Dilemmas. Social Behavior, 5: 247-260.

Bornstein, G. and Rapoport, Amnon (1988): intergroup Competition for the Provision of Step-Level Public Goods: Effects of Preplay Communication. European Journal of Social Psychology, 18: 125-142.

Bornstein, G.; Winter, E. and Goren, H. (1996): Experimental Study of Repeated Team-Games. European Journal of Political Economy, 12: 629-639.

Brewer, M.B. (1981): Ethnocentrism and Its Role in Interpersonal Trust. In Brewer, M.B. and Collins, B. (eds.): Scientific Inquiry and the Social Sciences. San Francisco: Jossey-Bass.

Brewer, M.B. (1996a): When Contact is not Enough: Social Identity and intergroup Cooperation. International Journal of Intercultural Relations, 20: 291-303.

Brewer, M.B. (1996b): In-Group Favoritism: The Subtle Side of intergroup Discrimination. In Messick, D. M. and Tenbrunsel, A. E. (eds.): Codes of Conduct. Behavioral Research Into Business Ethics. New York: Russell Sage Foundation.

Brewer, M.B. (1999): The Psychology of Prejudice: Ingroup Love or Outgroup Hate? Journal of Social Issues, 55(3): 429-444.

Brewer, M.B. and Miller, N. (1984): Beyond the Contact Hypothesis: Theoretical Perspectives on Desegregation. In Miller, N. and Brewer, M.B. (eds.): Groups in Contact: The Psychology of Desegregation. Orlando: Academic Press.

Brewer, M.B. and Miller, N. (1996): intergroup Relations. Buckingham: Open University Press.

Butler, D. and Stokes, D. (1974): Political Change in Britain: The Evolution of Electoral Choice. New York: St. Martin's.

Caporael, L.R.; Dawes, R.M., Orbell, J.M. and van de Kragt, A.J.C. (1989): Selfishness Examined: Cooperation in the Absence of Egoistic Incentives; and Response. Behavioral and Brain Sciences, 12: 683-739.

Chong, D. (1991): Collective Action and the Civil Rights Movement. Chicago: Chicago University Press.

Coenders, M. (2001): Nationalistic Attitudes and Ethnic Exclusionism in a Comparative Perspective. An Empirical Study of Attitudes Toward the Country and Ethnic Immigrants in 22 Countries. Nijmegen: ICS Dissertation Series.

Coleman, J.S. (1990): The Foundations of Social Theory. Cambridge (Mass.): The Belknap Press.

Coser, L.A. (1967): Continuities in the Study of Social Conflict. New York: Free Press.

Coser, L.A. (1968) [1956]: The Functions of Social Conflict. London: Routledge \& Kegan Paul.

Dawes, R.M. (1980): Social Dilemmas. Annual Review of Psychology, 31: 169-193.

Denitch, B. (1994): Ethnic Nationalism: The Tragic Death of Yugoslavia. Minneapolis: University of Minnesota Press.

Diez Medrano, J. (1994): The Effects of Ethnic Segregation and Ethnic Competition on Political Mobilization in the Basque Country, 1988. American Sociological Review, 59(6): 873-889.

Durkheim, E. (1984) [1893]: Division of Labor in Society. London: MacMillan.

Erev, I.; Bornstein, G. and Galili, R. (1993): Constructive intergroup Competition as a Solution to the Free Rider Problem: A Field Experiment. Journal of Experimental Social Psychology, 29: 463-478.

Esser, H. (1986): Ethnic Segmentation as the Unintended Result of Intentional Action. In Diekmann, A. and Mitter, P. (eds.): Paradoxical Effects of Social Behavior. Essays in Honor of Anatol Rapoport. Heidelberg: Physica.

Fearon, J. and Laitin, D. (1996): Explaining Interethnic Cooperation. American Political Science Review, 90(4): 715-735. 
Finkel, S.E. and Opp, K-D. (1991): Party Identification and Participation in Collective Political Action. Journal of Politics, 53(2): 339-371.

Flache, A. (1996): The Double Edge of Networks. An Analysis of the Effect of Informal Networks on Cooperation in Social Dilemmas. Amsterdam: Thesis Publishers.

Gellner, E. (1983): Nations and Nationalism. Ithaca, NY: Cornell University Press.

Goren, H. and Bornstein, G. (2000): The Effects of Intragroup Communication on intergroup Cooperation in the Repeated intergroup Prisoner's Dilemma (IPD) Game. Journal of Conflict Resolution, 44(5): 700-719.

Gould, R.V. (1991): Multiple Networks and Mobilization in the Paris Commune, 1871. American Sociological Review, 56: 716-729.

Gould, R.V. (1993): Collective Action and Network Structure. American Sociological Review, 58: $182-196$.

Gould, R.V. (1999): Collective Violence and Group Solidarity: Evidence from a Feuding Society. American Sociological Review, 64: 356-380.

Granovetter, M. (1985): Economic Action and Social Structure: The Problem of Embeddedness. American Journal of Sociology, 91: 481-510.

Heckathorn, D.D. (1989): Collective Action and the Second-Order Free-Rider Problem. Rationality and Society, 1: 78-100.

Heckathorn, D.D. (1990): Collective Sanctions and Compliance Norms: A Formal Theory of Group-Mediated Social Control. American Sociological Review, 55: 366-384.

Heckathorn, D. (1993): Collective Action and Group Heterogeneity: Voluntary Provision versus Selective Incentives. American Sociological Review, 58: 329-350.

Hogg, M.A. and Abrams, D. (1988): Social Identification. London: Routledge.

Horwitz, M. and Rabbie, J.M. (1982): Individuality and Membership in the intergroup System. In Tajfel, H. (ed.): Social Identity and intergroup Relations. Cambridge: Cambridge University Press.

Insko, C.A., Schopler, J., Drigotas, S.M., Graetz, K.A., Kennedy, J., Cox, Ch. and Bornstein, G. (1993): The Role of Communication in Interindividual-intergroup Discontinuity. Journal of Conflict Resolution, 37: 108-138.

Insko, C.A., Schopler, J., Graetz, K.A., Drigotas, S.M., Currey, D.P., Smith, S.L., Brazil, D. and Bornstein, G. (1994): Interindividual-intergroup Discontinuity in the Prisoner's Dilemma Game. Journal of Conflict Resolution, 38: 87-116.

Jankowski, M.S. (1991): Islands in the Street. Gangs and American Urban Society. Berkeley: University of California Press.

Kollock, P. (1998): Social Dilemmas: The Anatomy of Cooperation. Annual Review of Sociology, 24: 183-214.

Kosterman, R. and Feshbach, S. (1989): Toward a Measure of Patriotic and Nationalistic Attitudes. Political Psychology, 10: 257-274.

Kramer, R.M. and Brewer, M.B. (1984): Effects of Group Identity on Resource Use in a Simulated Common Dilemma. Journal of Personality and Social Psychology, 46: 1044-1057.

Kramer, R.M. and Brewer, M.B. (1986): Social Group Identity and the Emergence of Cooperation in Resource Dilemmas. In Wilke, H.; Messick, M. and Rutte, C. (eds.): Experimental Social Dilemmas. Frankfurt: Verlag Peter Lang.

Kratzer, J. (2001): Communication and Performance: An Empirical Study in Innovation Teams. Amsterdam: Thesis Publishers.

Kuran, T. (1995): Private Truths, Public Lies: The Social Consequences of Preference Falsification. Cambridge (Mass.): Harvard University Press. 
Leenders, R., Kratzer, J. and van Engelen, J.M.L. (2002): Managing Product Development Teams Effectively. In The PDMA Toolbook. New York: Wiley, 123-156.

LeVine, R.A. and Campbell, D.T. (1972): Ethnocentrism: Theories of Conflict, Ethnic Attitudes and Group Behaviour. New York: Wiley.

Liebrand, W.B.G. (1983): A Classification of Social Dilemma Games. Simulation and Games, 14: $123-138$.

Lindenberg, S. (1986): The Paradox of Privatization in Consumption. In Diekmann, A. and Mitter, P. (eds.): Paradoxical Effects of Social Behavior. Essays in Honor of Anatol Rapoport. Heidelberg: Physica.

Lindenberg, S. (1992): The Method of Decreasing Abstraction. In Coleman, J. S. and Fararo, T. J. (eds.): Rational Choice Theory. Advocacy and Critique. Newbury Park: Sage, 3-20.

Lindenberg, S. (1997): Grounding Groups in Theory: Functional, Cognitive, and Structural Interdependencies. Advances in Group Processes, 14: 281-331.

Macy, M.W. (1991): Learning to Cooperate: Stochastic and Tacit Collusion in Social Exchange. American Journal of Sociology, 97: 808-843.

Macy, M.W. (1993): Backward Looking Social Control. American Sociological Review, 58: 819-836.

Macy, M.W. (1997): Identity, Interest and Emergent Rationality: An Evolutionary Synthesis. Rationality and Society, 9(4): 427-448.

Marwell, G. and Oliver, P.E. (1993): Critical Mass in Collective Action. Cambridge: Cambridge University Press.

Marwell, G.; Oliver, P.E. and Prahl, R. (1988): Social Networks and Collective Action: A Theory of the Critical Mass. III. American Journal of Sociology, 94: 502-534.

Massey, G.; Hodson, R. and Sekulic, D. (1999): Ethnic Enclaves and Intolerance: The Case of Yugoslavia. Social Forces, 78(2): 669-673.

McAdam, D. (1986): Recruitment to High-Risk Activism: The Case of Freedom Summer. American Journal of Sociology, 92: 64-90.

Morris, S. (2000): Contagion. Review of Economic Studies, 67: 57-78.

Oberschall, A.R. (1973): Social Conflict and Social Movements. Englewood Cliffs, NJ: Prentice-Hall.

Oberschall, A.R. (1994): Rational Choice in Collective Protests. Rationality and Society, 6: 79-100.

Olson, M.Jr. (1965): The Logic of Collective Action. Cambridge (Mass.): Harvard University Press.

Olzak, S. (1986): A Competition Model of Ethnic Collective Action in American Cities, 1877-1889. In Olzak, S. and Nagel, J. (eds.): Competitive Ethnic Relations. Orlando (Florida): Academic Press, 17-46.

Olzak, S. (1992): The Dynamics of Ethnic Competition and Conflict. Stanford, CA: Stanford University Press.

Olzak, S.; Shanahan, S. and McEneaney, E.H. (1996): Poverty, Segregation, and Race Riots: 1960 to 1993. American Sociological Review, 61: 590-613.

Opp, K-D. and Gern, C. (1993): Dissident Groups, Personal Networks, and Spontaneous Cooperation - The East German Revolution of 1989. American Sociological Review, 58: 659-680.

Palfrey, T. and Rosenthal, H. (1983): A Strategic Calculus of Voting. Public Choice, 41: 7-53.

Parsons, T. (1937): The Structure of Social Action. Glencoe: Free Press.

Poundstone, W. (1992): Prisoner's Dilemma. New York: Doubleday. 
Rabbie, J.M. (1982): The Effects of intergroup Competition and Cooperation on Intragroup and Intergroup Relationships. In Derlega, V.J. and Grzelak, J. (eds.): Cooperation and Helping Behavior. New York: Academic Press.

Ragin, C.C. (1986): The Impact of Celtic Nationalism on Class Politics in Scotland and Wales In Olzak, S. and Nagel, J. (eds.): Competitive Ethnic Relations. Orlando (Florida): Academic Press.

Rapoport, Amnon and Bornstein, G. (1987): intergroup Competition for the Provision of Binary Public Goods. Psychological Review, 94: 291-299.

Rapoport, Anatol and Chammah, A.M. (1965): Prisoner's Dilemma: A Study in Conflict and Cooperation. Ann Arbor (MI): University of Michigan Press.

Richardson, L.F. (1948a): War-Moods: I. Psychometrika, 13: 147-174.

Richardson, L.F. (1948b): War-Moods: II. Psychometrika, 13: 197-232.

Richardson, L.F. (1951): Could an Arms-Race End Without Fighting? Nature, 168 (September 29): $567 ; 920$.

Richardson, L.F. (1960): Arms and Insecurity. (Ed. by Rashevsky, N. and Trucco, E.) Chicago: Quadrangle Press.

Sandell, R. and Stern, C. (1998): Group Size and the Logic of Collective Action: A Network Analysis of a Swedish Temperance Movement 1896-1937. Rationality and Society, 10(3): 327-345.

Schelling, T.C. (1971): Dynamic Models of Segregation. Journal of Mathematical Sociology, 1: $143-186$.

Schelling, T.C. (1978): Micromotives and Macrobehavior. New York: W. W. Norton.

Schopler, J. and Insko, C.A. (1992): The Discontinuity Effect in Interpersonal and intergroup Relations: Generality and Mediation. European Review of Social Psychology, 3: 121-151.

Sherif, M. (1966a): In Common Predicament. Social Psychology of intergroup Conflict and Cooperation. Boston: Houghton Mifflin.

Sherif, M. (1966b): Group Conflict and Co-operation. London: Routledge and Kegan Paul.

Sherif, M. and Sherif, C.W. (1969): Social Psychology. New York: Harper and Row.

Simmel, G. (1955) [1908]: Conflict. In: Conflict. The Web of Group-Affiliations. Glencoe, Illinois: Free Press.

Simmel, G. (1955) [1922]: The Web of Group-Affiliations. In: Conflict. The Web of Group-Affiliations. Glencoe, Illinois: Free Press.

Sumner, W.G. (1974) [1906]: Folkways. New York: Arno Press.

Suttles, G.R. (1967): The Social Order of the Slum. Chicago, IL: University of Chicago Press.

Tajfel, H. (1970): Experiments in intergroup Discrimination. Scientific American, 223: 96-102.

Tajfel, H. (1981): Human Groups and Social Categories. Studies in Social Psychology. Cambridge: Cambridge University Press.

Tajfel, H. (1982): Social Psychology of intergroup Relations. Annual Review of Psychology, 33: $1-39$.

Tajfel, H., Billig, M.G., Bundy, H.P. and Flament, C.I. (1971): Social Categorization and intergroup Behavior. European Journal of Social Psychology, 1: 149-178.

Tajfel, H. and Turner, J.C. (1986): The Social Identity Theory of intergroup Behavior. In Worchel, S. and Austin, W.G. (eds.): The Social Psychology of intergroup Relations. Chicago: Nelson-Hall.

Takács, K. (2001): Structural Embeddedness and intergroup Conflict. Journal of Conflict Resolution, 45 (6): 743-769.

Takács, K. (2002): Social Networks and intergroup Conflict. Groningen: ICS Dissertation Series.

Review of Sociology 9 (2003) 
Tingsten, H. (1963) [1937]: Political Behavior: Studies in Election Statistics. Totowa, NJ: Bedminster.

van de Kragt, A.J.C., Orbell, J.M. and Dawes, R.M. (1983): The Minimal Contributing Set as a Solution to Public Goods Problems. American Political Science Review, 77: 112-122.

van Lange, P.A.M., Liebrand, W.B.G., Messick, D.M. and Wilke, H.A.M. (1992): Social Dilemmas: The State of the Art. Introduction and Literature Review. In Liebrand, W.B.G., Messick, D.M. and Wilke, H.A.M. (eds.): Social Dilemmas. Theoretical Issues and Research Findings. Oxford, Pergamon Press.

Villareal, A. (2002): Political Competition and Violence in Mexico: Hierarchical Social Control in Local Patronage Structures. American Sociological Review, 67: 477-498.

Whyte, J.H. (1986): How is the Boundary Maintained between the two Communities in Northern Ireland? Ethnic and Racial Studies, 9: 219-234.

Williams, R. (1947): The Reduction of intergroup Tensions. A Survey of Research on Problems of Ethnic, Racial, and Religious Group Relations. New York: Social Science Research Council.

Wintrobe, R. (1995): Some Economics of Ethnic Capital Formation and Conflict. In Breton, A., Galeotti, G., Salmon, P. and Wintrobe, R. (eds.): Nationalism and Rationality. Cambridge: Cambridge University Press. 